\title{
Characteristics and trends in required home care by GPs in Austria: diseases and functional status of patients Gustav Kamenski*1, Waltraud Fink ${ }^{1}$, Manfred Maier ${ }^{1}$, Ingrid Pichler ${ }^{1}$ and Sonja Zehetmayer ${ }^{2}$
}

\author{
Address: ${ }^{1}$ Department of General Medicine (Head: Manfred Maier), Centre of Public Health, Medical University Vienna, Währingerstrasse 13a, A- \\ 1090 Wien, Austria and 2Section of Medical Statistics, Medical University Vienna, Spitalgasse 23, A-1090 Wien, Austria \\ Email: Gustav Kamenski* - kamenski@nextra.at; Waltraud Fink - waltraud.fink@gmx.at; Manfred Maier - manfred.maier@meduniwien.ac.at; \\ Ingrid Pichler - pichler@nanet.at; Sonja Zehetmayer - Sonja.zehetmayer@meduniwien.ac.at \\ * Corresponding author
}

Published: 01 October 2006

BMC Family Practice 2006, 7:55 doi:10.1186/147|-2296-7-55

This article is available from: http://www.biomedcentral.com//47/-2296/7/55

(C) 2006 Kamenski et al; licensee BioMed Central Ltd.

This is an Open Access article distributed under the terms of the Creative Commons Attribution License (http://creativecommons.org/licenses/by/2.0), which permits unrestricted use, distribution, and reproduction in any medium, provided the original work is properly cited.
Received: 13 April 2006

Accepted: 01 October 2006

\begin{abstract}
Background: Almost all societies carry responsibility towards patients who require continuous medical care at home. In many health systems the general practitioner cooperates with community based services of home care and coordinates all medical and non medical activities. In Austria the general practitioner together and in cooperation with relatives of the patient and professional organisations usually takes on this task by visiting his patients.

This study was carried out to identify diseases that need home care and to describe the functional profile of home care patients in eastern Austria.

Methods: Cross sectional observational study with 17 GP practices participating during 2 study periods in 1997 and in 2004 in eastern Austria. Each GP identified patients requiring home care and assessed their underlying diseases and functional status by filling in a questionnaire personally after an encounter. Patients in nursing homes were excluded. Statistical tests used were t-tests, contingency tables, nonparametric Wilcoxon signed rank sum test and Fisher-combination test.
\end{abstract}

Results: Patients with degenerative diseases of the central nervous system (65\%) caused by Alzheimer's disease and cerebrovascular occlusive disease and patients with degenerative diseases of the skeletal system (53\%) were the largest groups among the 198 (1997) and 26I (2004) home care cases of the II (1997) and I3 (2004) practices. Malignant diseases in a terminal state constituted only $5 \%$ of the cases. More than two thirds of all cases were female with an average age of 80 years. Slightly more than $70 \%$ of the patients were at least partially mobile.

Conclusion: Home care and home visits for patients with degenerative diseases of the central nervous and skeletal system are important elements of GP's work. Further research should therefore focus on effective methods of training and rehabilitation to better the mental and physical status of patients living in their private homes.

\section{Background}

Most societies carry responsibility towards patients requir- ing continuous medical attention and care at home [1-4]. In Austria the general practitioner together and in cooper- 
ation with relatives of the patient and professional organisations usually takes on this task by visiting his patients $[5,6]$. These patients need support for their chronic diseases such as sticks, absorbent pads or catheters, measures to prevent decubital ulcers or physiotherapy to improve their functional status, irrespective of whether they live in nursing homes or in their private homes [7,8]. An appropriate care for this group of patients increases the workload for the practice staff with regard to administration and organisation of all these home care related activities [9].

Detailed information about the diseases and the functional status of homecare patients not living in nursing homes is not available in Austria and there are no studies on the improvement of functional ability of the elderly population in the primary care setting. It was therefore the primary goal of this study to assess patients requiring homecare with regard to the disease(s) considered to be responsible for the need of homecare in the opinion of their GP. As secondary goals we tried to evaluate patients' functional status, the number of the physician-patient contacts as well as the number of care contacts of relatives and health care professionals with the patient. Furthermore, for the numbers available, we assessed the patients' degree of severity of illness according to the official grading system in Austria. The main goal of this study was to identify the diseases causing the need for home care and to evaluate the functional status of patients who are cared by GPs, patients' relatives and professional health services in the private homes of the patients.

Delivering health care services to the population and controlling the health care system is considered to be a public task in Austria. More than two thirds of this system is funded through social insurance contributions and general tax revenue. By paying a monthly compulsory contribution (including also employers' contributions) to social health insurance funds, nearly $99 \%$ of the Austrian population are insured and acquire entitlements to treatment as set out in the current general security provisions. Austrians are free to choose their GP or specialist and there exists no gate keeping function of the GP [10].

\section{Methods}

In a cross sectional design a total of 17 GP solo-practices of comparable size (each caring for approximately 2000 patients) participated in this observational study. Practices of this size are typical for most regions of Austria [10]. Participating practices are situated in and around Vienna within a radius of approximately 70 kilometres. So the study population consists of inhabitants of Vienna, but also of inhabitants of small towns and villages in rural regions. The study patients are living in small families or, if living alone, they are cared by family members who visit them in scheduled time intervals. The recruitment of GPs who regularly visit their patients, took place at various local district meetings by a personal invitation to take part in the study. There were 2 study periods, the first one in January and February 1997 and the second one in February, March and April 2004. 11 (1997) respectively 13 (2004) GP practices of the eastern part of Austria participated. 4 practices contributed only to the study period of 1997, while in 20046 new practices joined the group. 7 practices with identical GPs took part in both study periods.

In all participating practices, patients requiring homecare were identified and the underlying causal disease(s) as well as their functional status were assessed by the GP using a questionnaire [see Additional file 1]. Participating GPs were asked to fill in the questionnaire personally after an encounter with the patient, his relatives and a member of the professional home care organisation.

The questionnaire was designed to assess age and gender and other demographic data, the size of the GP practice, orientation of the patient and functional status, as well as the main reason for his need of homecare. In addition, the number of contacts between the patient and his GP as well as between those who cared for the patient and the practice were recorded based on the documentation system. In the questionnaire the official grading of patients requiring homecare according to Austrian legislation was also documented. This grading system is used within the Austrian health insurance system to provide financial support to the patient and is executed by a special physician employed by the health insurance company. It is based on the number of hours per month needed for the care of the patient. Grade 1 means a minimum of 50 hours and grade 7 means a maximum of 180 hours for the care and includes the total immobility of the patient.

All patients who were unable to regularly execute activities of daily life by themselves and therefore required the help of other people were included in the study. Patients living in nursing homes were excluded.

Data were assessed by the statistical programs EPI Info, Version 6 and SAS 8.

Methods used were t-tests for the comparison of age between women and men in 1997 and in 2004 and contingency tables with a chi-square test for the comparison of the degrees of the official grading system between 1997 and 2004. Here, p-values $<0.05$ were considered as significant. For the comparison of the frequency of diseases between 1997 and 2004 on the one hand a nonparametric Wilcoxon signed rank test (paired analyses) for the practices taking part in both study periods and on the other 
hand a Wilcoxon rank sum test (unpaired analysis) for practices taking part in only one period was calculated for each disease group.

Then a Fisher-combination test was performed for the resulting independent $\mathrm{p}$-values, that means the comparison between 1997 and 2004 was considered as significant if the product of the two p-values was $<0.00870$ (twosided test with an overall significance level 0.05) [11]

\section{Results}

Between 18 and 20 patients per GP required homecare in both study periods.

On average the GP visited these patients 2.2 times per month in 1997 and 2.7 times per month in 2004. The number of contacts between the relatives or the nursing professionals and the GP practice was 1.8 times per month in 1997 and 1.4 times per month in 2004 (figures not shown in table).
Table 1 shows the number of participating practices, patients' characteristics and the degrees of the official grading system during the 2 study periods. 1997 as well as 2004 there was a significant difference in the age between men and women. In the degrees of the official grading system there was a tendency towards more patients in the group of the less severe cases (groups $1+2$ ) in the year 2004 . About $85 \%$ of the patients were taken care of by relatives in the year 1997 as well as 2004 while $14.2 \%$ (1997) and 38.1\% (2004) of the patients were attended by nursing professionals.

Table 2 shows the functional status of the patients requiring home care and compares the assessment made in 1997 with the data from the second study period in 2004 .

The assessment of the functional status in 1997 shows that $69 \%$ were not totally mobile, $43 \%$ were mobile only with some support, and $23 \%$ were bedridden. About 50\%

Table I: Number of practices, patients' characteristics and grading according to the official Austrian grading system

\begin{tabular}{|c|c|c|}
\hline Year & 1997 & 2004 \\
\hline Participating practices & $N=11$ & $N=13$ \\
\hline \multirow[t]{2}{*}{ Total number of patients } & $N=198$ & $N=26 I$ \\
\hline & $\mathrm{n}(\%)$ & $\mathrm{n}(\%)$ \\
\hline \multicolumn{3}{|l|}{ Sex } \\
\hline $\mathrm{m}$ & $56(28.3)$ & $79(30.3)$ \\
\hline f & $142(7 \mid .7)$ & $182(69.7)$ \\
\hline \multicolumn{3}{|l|}{ Mean age } \\
\hline $\mathrm{m} / \mathrm{f}$ & 77.2 (SD I7.5) & 79.9 (SD I3.7) \\
\hline $\mathrm{m}^{*}$ & 72.1 (SD 18.2) & $76.3(\mathrm{SD} 16.1)$ \\
\hline$f^{*}$ & 79.2 (SD I6.8) & 81.4 (SD I2.2) \\
\hline Married & $56(28.3)$ & $76(29.1)$ \\
\hline Divorced & $4(2.0)$ & $19(7.3)$ \\
\hline Widowed & $110(55.6)$ & $139(53.3)$ \\
\hline Single & $28(14.1)$ & $27(10.3)$ \\
\hline \multicolumn{3}{|l|}{ Former occupation } \\
\hline Housewife & $81(40.9)$ & $96(36.8)$ \\
\hline Self-employed & $4 \mathrm{I}(20.7)$ & $46(17.6)$ \\
\hline Employed & $62(31.3)$ & $106(40.6)$ \\
\hline None & $14(7.1)$ & $13(5.0)$ \\
\hline Care provided by & $\dagger N=197$ & $\dagger N=257$ \\
\hline Relatives & $169(85.8 \%)$ & $218(84.8 \%)$ \\
\hline Professional health care services & $28(14 \%)$ & $83(38.1 \%)$ \\
\hline \multirow[t]{2}{*}{ Degrees of the official grading system } & \multicolumn{2}{|c|}{ Number of patients (attached to degree $1-7$ ) } \\
\hline & $\mathrm{n}(\%)$ & n (\%) \\
\hline $1+2 \ddagger$ & $43(24.7)$ & $109(51.9)$ \\
\hline $3+4$ & $103(59.2)$ & $85(40.5)$ \\
\hline \multirow[t]{2}{*}{$5+6+7$} & $28(16.1)$ & $16(7.6)$ \\
\hline & $+174(100.0)$ & $+210(100.0)$ \\
\hline
\end{tabular}

*1997 as well as 2004 there was a significant difference in the age between men and women $[p=0.0093(1997) ; p=0.014(2004)]$ in the $t$-test. $\dagger$ Assessment was not available in all cases of the years 1997 and 2004

$\ddagger$ Compared with the year 1997 there was a tendency towards more patients in the group of the less severe cases $($ degree I+2) in the year $2004(P$ $<0.0001$ ) in the official grading system. 
Table 2: Functional status of patients of all practices in the years $1997(\mathbf{N}=198)$ und $2004(N=26$ I)

\begin{tabular}{|c|c|c|c|c|c|c|}
\hline \multirow[t]{3}{*}{ Year } & 1997 & 2004 & 1997 & 2004 & 1997 & 2004 \\
\hline & \multicolumn{2}{|c|}{ Yes } & \multicolumn{2}{|c|}{ In part } & \multicolumn{2}{|c|}{ No } \\
\hline & $\mathrm{n}$ & $(\%)^{*}$ & $\mathrm{n}$ & $(\%)^{*}$ & $\mathrm{n}$ & $(\%)^{*}$ \\
\hline Oriented(time) & $116(58.6)$ & $182(69.7)$ & $31(15.7)$ & $51(19.5)$ & $51(25.8)$ & $28(10.7)$ \\
\hline Oriented(location) & 143 (72.2) & $213(81.6)$ & $26(13.1)$ & $33(12.6)$ & $29(14.6)$ & $15(5.7)$ \\
\hline Mobile(complete) & $42(21.2)$ & $67(25.7)$ & $19(9.6)$ & $44(16.9)$ & $137(69.2)$ & $150(57.5)$ \\
\hline Mobile with support & 85 (42.9) & $148(56.7)$ & $26(13.1)$ & $46(17.6)$ & $87(44.0)$ & $67(25.7)$ \\
\hline Bedridden & $45(22.7)$ & $27(10.3)$ & $29(14.6)$ & $39(14.9)$ & $124(62.6)$ & $195(74.7)$ \\
\hline Incontinent & $97(49.0)$ & $91(34.9)$ & $26(13.1)$ & $56(21.5)$ & $75(37.9)$ & $114(43.7)$ \\
\hline Able to communicate & $175(88.4)$ & $232(88.9)$ & $10(5.1)$ & $18(6.9)$ & $13(6.6)$ & II (4.2) \\
\hline Able to dress by themselves & $69(34.8)$ & $125(47.9)$ & $32(16.2)$ & $80(30.6)$ & $97(49.0)$ & $56(21.5)$ \\
\hline Personal hygiene & $46(23.2)$ & $79(30.3)$ & $45(22.7)$ & 91 (34.9) & $107(54.0)$ & $91(34.9)$ \\
\hline Ability to eat by themselves & $136(68.7)$ & $208(79.7)$ & $30(15.2)$ & $29(11.1)$ & $32(16.2)$ & $24(9.2)$ \\
\hline Ability to take medication by themselves & $57(28.8)$ & $118(45.2)$ & $22(11.1)$ & $38(14.6)$ & $119(60.0)$ & $105(40.2)$ \\
\hline Danger of falls & $155(78.3)$ & $185(71.0)$ & $19(9.6)$ & $22(8.4)$ & $24(12.1)$ & $54(20.7)$ \\
\hline \multicolumn{7}{|c|}{ Frequency of home care visits (provided by relatives or health care professionals) } \\
\hline Year & & \multicolumn{2}{|c|}{1997} & \multicolumn{2}{|c|}{2004} & \\
\hline Number of home care visits per day & & \multicolumn{2}{|c|}{ n (\%) } & \multicolumn{2}{|c|}{ n (\%) } & \\
\hline Ix/day & & \multicolumn{2}{|c|}{ II (5.8) } & \multicolumn{2}{|c|}{$49(20.3)$} & \\
\hline $2 x /$ day & & \multicolumn{2}{|c|}{$22(11.5)$} & \multicolumn{2}{|c|}{$59(24.5)$} & \\
\hline $3 x /$ day & & \multicolumn{2}{|c|}{$43(22.5)$} & \multicolumn{2}{|c|}{$38(15.8)$} & \\
\hline Continuous care & & \multicolumn{2}{|c|}{$115(60.2)$} & \multicolumn{2}{|c|}{$95(39.4)$} & \\
\hline Sum & & \multicolumn{2}{|c|}{$191+(100)$} & \multicolumn{2}{|c|}{$241+(100)$} & \\
\hline
\end{tabular}

*All percentage rates apply to the totality of cases $\mathrm{N}=198(1997)$ and $\mathrm{N}=26 \mathrm{I}$ (2004)

flt was only possible to assess the number of home care visits in 191 of 198 patients (1997) and in 241 of 26I patients (2004)

of the patients could not dress themselves or take care of their hygiene.

There was a trend in direction of an improvement of the most of the functional parameters in 2004.

Table 3 summarizes the underlying diseases mainly responsible for the need for homecare of the patients. As can be seen diseases of the central nervous and of the skeletal system were the main reasons for requiring home care. Diseases of the central nervous system were responsible for 67\% (1997) and 63\% (2004) of all home care cases. Diseases of the joints and the vertebral column significantly increased from $42 \%$ to $65 \%$ in 2004 .

Cardiovascular diseases constituted 39\% of the cases requiring home care in both periods.

The percentage of patients requiring home care who suffered from the complications of long lasting diabetes increased from 11\% (1997) to 19\% (2004).

The group of the other diseases consisted of 32\% (1997) and $24 \%$ (2004) of all cases.

Table 4 Among the diseases of the central nervous system, degenerative disorders (mainly dementia of Alzheimer's type) followed by vascular reasons were leading prob- lems. Among diseases of the joints and the vertebral column, again degenerative problems were the main reason for requiring homecare. Coronary artery disease and cardiac insufficiency were the main reasons among the diseases of the cardiovascular system. Among metabolic diseases diabetes was the leading cause for the requiring of home care. Among the other diseases senile marasmus (chronic dehydration and malnutrition not caused by certain disease) was the leading cause. Malignancies in the end stage played at least quantitatively a minor role in both investigation periods.

\section{Discussion}

As far as we are aware this is the first survey of patients requiring home care from the perspective of the GP in Austria. As an essential result of the study it turned out that the focal point in the management of the diseases of GPs' home care patients is not the cancer patient in the terminal stage, but the patient with degenerative diseases of the CNS and the musculo-skeletal system.

About $85 \%$ of the patients were cared for by one or more of their relatives. $2 / 3$ of the patients were female and 5 years older than males. This correlates with the higher life expectancy for women $[12,13]$.

The number of 2.2 (1997) and 2.7 (2004) home visits per month, was rather low considering the number of coexist- 
Table 3: Groups of diseases causing the need for home care

\begin{tabular}{|c|c|c|}
\hline Year & $\begin{array}{l}1997 \\
N=198\end{array}$ & $\begin{array}{l}2004 \\
N=261\end{array}$ \\
\hline Diseases of the CNS & $n=133(67.2 \%)$ & $n=165(63.2 \%)$ \\
\hline *ICD I0: F00, F0I, G20, G30, G3I, G35, G46, G80, G8I, G83, I6I, 163, 164, T90 & \multicolumn{2}{|c|}{ (unpaired $p=0.83$, paired $p=0.22$, combination $p=0.18$ ) } \\
\hline Diseases of joints and vertebra $\dagger$ & $n=84(42.4 \%)$ & $\mathrm{n}=168(64.9 \%)$ \\
\hline *ICD I0: M05, M06, MI5, MI6, MI7, M42, M47, M5I, M53, M80 & \multicolumn{2}{|c|}{ (unpaired $p=0.03$, paired $p=0.08$, combination $p=0.002$ ) } \\
\hline Diseases of the cardiovascular system & $\mathrm{n}=78(39.4 \%)$ & $\mathrm{n}=102(39.2 \%)$ \\
\hline *ICD 10: 108, III, I20, 125, 142, 150, J42, J43, J45 & \multicolumn{2}{|c|}{ (unpaired $p=0.75$, paired $p=0.94$, combination $p=0.7$ ) } \\
\hline Metabolic diseases $\ddagger$ & $\mathrm{n}=30(15.2 \%)$ & $n=60(23.0 \%)$ \\
\hline *ICD I0: EIO, EII, K7I, K74, NI8 & \multicolumn{2}{|c|}{ (unpaired $p=0.59$, paired $p=0.03$, combination $p=0.019$ ) } \\
\hline Other diseases & $\mathrm{n}=64(32.2 \%)$ & $\mathrm{n}=63(24.2 \%)$ \\
\hline *ICD 10: C00-C97, E4I, E64, H54, H80 & \multicolumn{2}{|c|}{ (unpaired $p=0.34$, paired $p=0.69$, combination $p=0.23$ ) } \\
\hline
\end{tabular}

*To point out the most frequent diseases of each group as they are coded by the International Classification of Diseases (ICD I0) system. †Significant difference in the frequency of the diseases of joints and vertebra between 1997 and 2004.

¥There is a trend of an increasing frequency of metabolic diseases between 1997 and 2004.

ing diseases. A possible explanation for this result could be that regular home visits by the GP and other health care professionals support the relatives providing care, foster the health status of patients and help to prevent deterioration [14].

Concerning the change in the proportion that has permanent home care, going from $60 \% 1997$ to $40 \%$ in 2004 we do not believe that this change is due to changed living arrangements, as these did not change appreciably in this area. Elderly people, as mentioned above, usually live alone (regularly visited by their children or other relatives living close by) or in small families. Also 1997 it was already very infrequent that elderly people lived in extended families and this situation did not change until now.

A possible explanation for the reduction of elderly people needing permanent care could be that the number of nursing homes has increased and that access to nursing homes is more easy and better accepted $[10,13]$.

Comparing the functional parameters between 1997 and 2004 shows a trend in the direction of an improvement in most of the parameters assessed. The improvement in the functional parameters parallels the decrease in the severity of the degrees of the official Austrian grading system. This trend could indicate that patients with more serious medical problems are kept in nursing homes, as we found evidence for an increasing trend (a plus of 20,3\% between 1997 and 2004) for institutionalization of elderly people in this area with a rate of 126 for every 1000 people aged 75 or older $[10,13]$. A more optimistic interpretation could be that the continuous care by relatives, professionals and physicians improves functional parameters over time.

Diseases of the CNS constituting the majority of the cases remained equally frequent and cause a heavy burden for those who care for these patients. Two thirds of all patients show an orientation in time and location, which can be explained by the fact that certain diseases of the CNS (e.g. strokes, sclerosis, sequelaes of brain trauma, Parkinson's disease) do not regularly cause an impaired orientation, but are nevertheless impairing the patient enough to make him unable to care for himself [15-18].

The increasing number of the diseases of the musculoskeletal system is not surprising, considering the general trend in civilized nations towards a high prevalence of musculo-skeletal disorders [19]. Obviously there exists a contradiction between the bettering of the functional parameters and the increasing number of musculo-skeletal diseases, which possibly can be explained by an increasing number of less severe cases despite the higher mean age of patients in the second observation period of 2004.

The tendency towards more severe cases of diabetes parallels the increasing prevalence of diabetes at the national $[20,21]$ and international level [22].

Malignant diseases constituted only a small proportion of the diseases leading to the need for home care. Despite their low number, patients suffering from terminal malignant disease require special competence for example with 
Table 4: Diseases causing the need for home care in detail

\begin{tabular}{|c|c|c|}
\hline Year & 1997 & 2004 \\
\hline Central nervous system & $N=133(67.2 \%)$ & $N=165(63.2 \%)$ \\
\hline Dementia degenerative & $\mathrm{n}=65(32.8 \%)$ & $\mathrm{n}=97(37.2 \%)$ \\
\hline vascular & $\mathrm{n}=57(28.8 \%)$ & $\mathrm{n}=80(30.6 \%)$ \\
\hline Congenital & $\mathrm{n}=1 \mathrm{I}(5.6 \%)$ & $\mathrm{n}=8(3.1 \%)$ \\
\hline Toxic (hepatic, uremic, ethylic.) & $\mathrm{n}=7(3.5 \%)$ & $\mathrm{n}=14(5.4 \%)$ \\
\hline Inflammatory (status post.) & $\mathrm{n}=5(2,5 \%)$ & $\mathrm{n}=5(1.9 \%)$ \\
\hline Epileptic & $\mathrm{n}=4(2 \%)$ & $\mathrm{n}=8(3.1 \%)$ \\
\hline Posttraumatic & $\mathrm{n}=4(2 \%)$ & $\mathrm{n}=7(2.7 \%)$ \\
\hline Joints and vertebra & $N=84(42.4 \%)$ & $N=168(64.4 \%)$ \\
\hline Degenerative & $\mathrm{n}=7 \mathrm{I}(35.8 \%)$ & $n=153(58.6 \%)$ \\
\hline Posttraumatic & $\mathrm{n}=\mathrm{II}(5.6 \%)$ & $n=25(9.6 \%)$ \\
\hline Inflammatory (status post) & $\mathrm{n}=6(3.0 \%)$ & $\mathrm{n}=24(9.2 \%)$ \\
\hline Congenital & $\mathrm{n}=3(1.5 \%)$ & $\mathrm{n}=5(1.9 \%)$ \\
\hline Cardiorespiratory and vascular system & $N=78(39.4 \%)$ & $N=102(39 \%)$ \\
\hline Coronary heart disease and chronic heart failure & $\mathrm{n}=70(35.4 \%)$ & $\mathrm{n}=84(32.2 \%)$ \\
\hline COPD und asthma & $\mathrm{n}=1 \mathrm{I}(5.6 \%)$ & $\mathrm{n}=30(11.5 \%)$ \\
\hline Peripheral arterial occlusive disease & $\mathrm{n}=8(4.0 \%)$ & $\mathrm{n}=29(11.1 \%)$ \\
\hline Metabolic diseases & $N=30(15.2 \%)$ & $N=60(23.0 \%)$ \\
\hline Diabetes & $n=22(11,1 \%)$ & $n=49(18.8 \%)$ \\
\hline Hepatic & $n=6(3.0 \%)$ & $\mathrm{n}=10(3.8 \%)$ \\
\hline Renal & $\mathrm{n}=7(3.5 \%)$ & $\mathrm{n}=7(2.7 \%)$ \\
\hline Other diseases & $N=64(32.3 \%)$ & $N=63(24.1 \%)$ \\
\hline Marasmus senilis & $\mathrm{n}=38(19.2 \%)$ & $n=25(9.6 \%)$ \\
\hline Blindness & $\mathrm{n}=14(7.1 \%)$ & $\mathrm{n}=25(9.6 \%)$ \\
\hline Deafness & $\mathrm{n}=14(7.1 \%)$ & $\mathrm{n}=18(6.9 \%)$ \\
\hline Terminal malignant disease & $\mathrm{n}=10(5.1 \%)$ & $\mathrm{n}=1 \mathrm{I}(4.2 \%)$ \\
\hline
\end{tabular}

Note: All percentage rates apply to the totality of cases $N=198$ (1997) and N = 26I (2004)

regard to pain management. The cooperation between the patient, relatives, nursing professionals and palliative care teams is therefore of high importance [23-26].

The high prevalence of marasmus senilis (19 respectively $10 \%)$ compares well with the results of other studies which show figures between 5 and 37\% [27,28].

One of the strengths of our study is that it gives a first insight in the underlying diseases leading to the need of home care and in the functional status of patients living in their private homes who are cared for there by their GPs. Another perhaps unexpected result is the high involvement of the relatives in the caring process in addition to professional care givers.

One of the main limitations of our study is the small number of practices in the restricted geographical area of eastern Austria. Another limitation is that the practices of the two study periods were only partially identical. So the comparison of the results of the two periods could have been biased by this.

In accordance with the existing literature we found that degenerative diseases of the brain and the skeletal system are the main reason for chronic disability also in our group of home cared patients and that home visits play an important role in the process of continuous home care $[1,5,6,8,12,17,19]$.

\section{Conclusion}

Long term care and home care for patients with degenerative diseases of the central nervous and skeletal system are important elements of GP's work. Further research in general practice and family medicine should therefore focus on effective methods of training and rehabilitation to bet- 
ter the mental and physical status of this group of patients living in their private homes.

To contextualize the results of our geographically limited study and to examine if they are valid for the rest of Austria and the other countries of the EC, further research work is necessary, as the problem of an increasing number of elderly people requiring home and long term care affects many health care systems.

\section{Competing interests}

The author(s) declare that they have no competing interests.

\section{Authors' contributions}

GK, as the main author of the study initiated, discussed and organized the concept of the study from the beginning including acquisition, analysis and interpretation of data.

WF participated in the study by helping to draft the manuscript and to check the relevant literature.

MM contributed to the study by critically analyzing especially the data and conclusions of the first study period and by revising the concept, results and conclusions of the whole study.

IP participated especially in drawing up the first concept of the study and she helped also in building up the small research network of practices.

SZ was involved in the study by doing the statistics and by critically revising the final results and conclusions of the study.

All authors read and approved the final manuscript.

\section{Additional material}

\section{Additional file 1}

Study questionnaire. This questionnaire had to be filled in personally by the GP after an encounter.

Click here for file

[http://www.biomedcentral.com/content/supplementary/14712296-7-55-S1.doc]

\section{Acknowledgements}

The authors of the study did not receive any funding.

The authors wish to thank the following Austrian primary care physicians and their staff: K. Danzinger, W. Fink, A. Groihofer, K. Haindl, R. HoffmannD, E. Maier, G. Pichler, I. Pichler, P. Pichler, C. Schramhauser, C. Sellner, A. Sperlich, H. Tönies, G. Tutsch, A. W-Mitteräcker, P. Zapotoczky.

\section{References}

I. Report on the Aged $4^{\text {th }}$ report on the situation of the older generation in the Federal Republic of Germany: Risks, quality of life and care of people advanced in years under special consideration of demential disorders. DZA I 2101 Berlin; 2002.

2. Avery AJ, Groom LM, Brown KP, Thornhill K, Boot D: The impact of nursing home patients on prescribing costs in general practice. I Clin Pharm Ther 1999, 24:357-363.

3. Schick B, Dohner H: Interdisciplinary cooperation in the primary care of elderly patients-results with consequences for general practice. Gesundheitswesen 1996, 58:126-I3I.

4. Westert GP, Satariano WA, Schellevis FG, van den Bos GA: Patterns of comorbidity and the use of health services in the Dutch population. Eur J Public Health 200I, I I:365-372.

5. Bergeron R, Laberge A, Vezina L, Aubin M: Which physicians make home visits and why? A survey. CMAJ 1999, I 6 I:369-373.

6. Keenan JM, Bland CJ, Webster L, Myers S: The home care practice and attitudes of Minnesota family physicians. J Am Geriatr Soc 1991, 39: I 100-II04.

7. Madigan E, Neff DF: Care of patients with long-term indwelling urinary catheters. Online J Issues Nurs 2003, 8:7.

8. Modin S, Furhoff AK: Care by general practitioners and district nurses of patients receiving home nursing: a study from suburban Stockholm. Scand J Prim Health Care 2002, 20:208-2I 2.

9. Scott $A$, Wordsworth $S$ : The effects of shifts in the balance of care on general practice workload. Fam Pract 1999, 16:12-17.

10. Hofmarcher Maria , Rack Herta : Health Care Systems in Transition: Austria. The European Observatory on Health Care systems 2001 .

II. Bauer P, Koehne K: Evaluation of experiments with adaptive interim analysis. Biometrics 1994, 50:1029-1041.

12. Austrian Health Report. Vienna 2003.

13. Statistics Austria general and Population Preliminary death tables. Vienna; 2002. Publication series of Ministry of Social Security 2006.

14. Vass M, Avlund K, Kvist K, Hendriksen C, Andersen CK, Keiding N Structured home visits to older people. are they only of benefit for women? A randomised controlled trial. Scand J Prim Health Care 2004, 22: 106-II.

15. Brodaty H, Green A: Who cares for the carer? The often forgotten patient. Aust Fam Physician 2002, 31:833-836.

16. Huston PG: Family care of the elderly and caregiver stress. Am Fam Physician 1990, 42:671-676.

17. Kramer B]: Husbands caring for wives with dementia: a longitudinal study of continuity and change. Health Soc Work 2000 , 25:97-107.

18. Ward S, Opie J, O'Connor DW: Family carer's responses to behavioural and psychological symptoms of dementia. Int J Geriatr Psychiatry 2003, I 8:1007-1012.

19. Thomas E, Wilkie R, Peat G, Hill S, Dziedzic K, Croft P: The North Straffordshire Osteoarthritis Project - I NORSTOP: prospective, 3-year study of the epidemiology and management of clinical osteoarthritis in a general population of older adults. BMC Musculoskelet Disord 2004, 5:2.

20. Austrian Diabetes Report. Vienna 2004.

21. Harris MI, Flegal KM, Cowie CC, Eberhardt MS, Goldstein DE, Little RR, Wiedmeyer HM, Byrd-Holt DD: Prevalence of diabetes, impaired fasting glucose and impaired glucose tolerance in US adults: The third National Health and Nutrition Examination Survey 1988-1999. Diabetes Care 1998, 2 I:5 I8-524.

22. World Health Organisation (WHO): Nutrition, diet and the prevention of chronic diseases. Report of a joint WHO/FAO expert consultation. Technical report series 9/6. Geneva 2003.

23. Walsh D, Regan J: Terminal care in the home- the general practice perspective. Ir med J 200I, 94:9-II.

24. Beaver K, Luker KA, Woods S: Primary care services received during terminal illness. Int J Palliat Nurs 2000, 6:220-227.

25. Kevin Yuen J, Margaret Behrndt M, Jacklyn C, Mitchell GK: Palliative care at home: general practitioners working with palliative care teams. MJA 2003:38-40.

26. Zepetella G: How do terminal ill patients at home take their medication? Palliat Med 1999, I 3:469-75.

27. Saletti A, Johansson L, Yifter-Lindgren E, Wissing $U$, Osterberg $K$, Cederholm T: Nutritional status and a 3-year follow-up in elderly receiving support at home. Gerontology 2005, 5 I(3): I92-8. 
28. Guigoz $\mathrm{Y}$, Lauque $\mathrm{S}$, Vellas $\mathrm{B}$ ): Identifying the elderly at risk for malnutrition: The Mini Nutritional assessment. Clin Geriatr Med 2002, 18(4):737-57.

\section{Pre-publication history}

The pre-publication history for this paper can be accessed here:

http://www.biomedcentral.com/1471-2296/7/55/prepub

Publish with Bio Med Central and every scientist can read your work free of charge

"BioMed Central will be the most significant development for disseminating the results of biomedical research in our lifetime. " Sir Paul Nurse, Cancer Research UK

Your research papers will be:

- available free of charge to the entire biomedical community

- peer reviewed and published immediately upon acceptance

- cited in PubMed and archived on PubMed Central

- yours - you keep the copyright 